\title{
INSPIRACIÓN POÉTICA Y RESPIRACIÓN EN LA OBRA DE ANTONIO COLINAS
}

\author{
Rocio Badía Fumaz \\ Westfälische Wilhelms-Universität Münster \\ rocio.badia@uni-muenster.de
}

\section{RESUMEN / ABSTRACT}

Más allá de la conexión etimológica entre respiración e inspiración poética, el poeta español Antonio Colinas indaga en sus ensayos literarios y en su obra poética en la relación entre ambas funciones. Esta investigación pretende mostrar cómo la respiración origina y permite cierto tipo de creación poética que tiene como fin la armonía del hombre con el mundo. Para ello, se estudia el ritmo como elemento común, la percepción fenomenológica de la naturaleza y el aroma como imagen material de la respiración.

Palabras Clave: Antonio Colinas, creación poética, respiración, poéticas explícitas, autopoéticas.

Beyond the etymological connection between breath and poetic inspiration, the Spanish poet Antonio Colinas explores the relationship between this two functions in his literary essays and his poetry too. This research aims to show how the breath originates and allows certain kind of poetic creation that aims to achieve harmony between man and the world. In order to do that, the rhythm as a common element, the phenomenological perception of nature and aroma as a materialisation of breathing are studied.

KEYWORDS: Antonio Colinas, poetic creation, breathing, explicit poetics, autopoetics.

\section{INTRODUCCIÓN}

Antonio Colinas nace en La Bañeza (León, España) en 1946. La amplitud de su obra tanto literaria como no literaria, que abarca poesía, novela, libros de viajes, biografía, estudios y ensayos de contenido literario, traducciones 
o columnas periodísticas, le convierte en uno de los autores contemporáneos más reconocidos por la crítica internacional. Desde que en 1976 recibiera el Premio de la Crítica por su volumen Sepulcro en Tarquinia, su obra ha recibido continuados reconocimientos, entre los que destacan el Premio Nacional de Literatura por la antología poética Poesía, 1967-1982 (1982), Premio Internacional Jovellanos de Ensayo por Sobre la Vida Nueva (1996), el Premio Nacional de Traducción (2005) por la traducción de la obra completa de Salvatore Quasimodo o el máximo reconocimiento para la poesía en lengua española que supone el Premio Reina Sofía de Poesía Iberoamericana (2016).

Pese a que con cierta reiteración la crítica ha situado a Antonio Colinas dentro de los poetas novísimos o la Generación del 70, su obra solo presenta cierta afinidad temática en aspectos concretos que, por lo demás, se alejan de la generación novísima en cuanto a la motivación que los origina. No en vano, uno de los rasgos característicos de este poeta es su individualidad, la libertad con la que enfrenta la creación sin buscar la protección del paraguas generacional.

Dentro de su producción poética pueden reconocerse dos grandes espacios poéticos: uno de plenitud sensorial (Preludios a una noche total, Truenos y flautas en un templo, Sepulcro en Tarquinia, incluso Noche más allá de la noche, obra clave que puede concebirse como quicio entre uno y otro momento poético), otro de progresivo adelgazamiento (Blanco / Negro, Jardín de Orfeo, Tiempo y abismo entre otros). En mi trabajo voy a abordar fundamentalmente esta última tendencia, en tanto que el fenómeno que quiero estudiar, la relación entre inspiración poética y respiración, es más patente en ella.

Sin embargo, esta articulación no aparece sólo en la poesía de Colinas. La continuada producción de poéticas explícitas o ensayos de contenido literario favorecen el abordaje teórico del mismo fenómeno por parte del autor, hecho que, curiosamente, no se ciñe en exacta correspondencia con su discurso poético, sino que aparece mucho más prontamente en sus textos ensayísticos. Esta ausencia de paralelismo exacto entre poética explícita o autopoética de un autor y su producción literaria es uno de los rasgos característicos del tipo de texto, como vienen apuntando estudios recientes (Badía Fumaz 2015, Lucifora 2015). Para comprender el lugar que ocupa un motivo en el pensamiento literario de un autor debe asumirse de forma consciente esta particularidad.

En estas páginas me propongo estudiar la relación que el poeta español Antonio Colinas establece entre la inspiración poética y un fenómeno corporal, el de la respiración. La estrecha relación de una actividad intelectual como la 
creación literaria con aspectos de lo biológico no sorprende en el pensamiento de Colinas, estando muy desarrollada sobre todo en su obra poética pero asimismo con una incidencia notable en su continuada reflexión ensayística ${ }^{1}$.

A menudo, esta vinculación entre palabra poética y cuerpo se presenta precisamente como una incorporación de la palabra o el canto en el cuerpo del poeta, dando lugar a imágenes sorprendentes ("Háblame a media voz, dime qué hay por el cauce / sonoro de tus venas"2 (Colinas, El río 51) y trasluciendo matices de la idea de creación asumida por el leonés: "Van a venir los pájaros / a picar en mi sangre, a derramar sus locos / trinos por cada vena de estos brazos tendidos, / de estos brazos repletos tan sólo de abandono" (El río 38).

Estos versos nos devuelven una bella imagen de la inspiración, donde la voz de los pájaros -lenguaje de los ángeles para René Guénon, con toda la importancia de la figura del ángel como mediador entre el poeta y la divinidad-se incorpora directamente al fluir de la sangre del yo poético ${ }^{3}$. Estamos ante una inspiración por vía directa entonces, por la inclusión del discurso en el cuerpo del poeta que lleva a la participación total del hombre en esa naturaleza poética que no calla.

\footnotetext{
Entre su obra ensayística destaca el lugar de la respiración en los artículos recogidos en El sentido primero de la palabra poética (1989 y 2008), Sobre la Vida Nueva (1996) y los dos volúmenes de Del pensamiento inspirado (2001). Dentro de su obra poética la respiración aparece en casi todos sus libros, aunque puede destacarse la conexión entre palabra y respiración en obras como Noche más allá de la noche (1983), Jardín de Orfeo (1988), Los silencios de fuego (1992) o Tiempo y abismo (2002), además de suponer una de las claves interpretativas o idea fundamental de los tres Tratados de armonía (1991, 1999, 2010), género particular que su autor denomina "contemplaciones", a caballo entre la reflexión ensayística y la prosa poética. Resulta además representativo que una de las diversas antologías poéticas de la obra de Colinas haya recibido el significativo título En la luz respirada (2004), título por lo demás de un poema recogido en Tiempo y abismo que sintetiza esta idea reiterativa en la obra del leonés.

Para citar los poemas de Colinas hago uso de la recopilación de su obra completa publicada en 2004 por la editorial Visor bajo el título El río de sombra. Treinta y cinco años de poesía, 1967-2002. Existe una recopilación más reciente editada por Siruela y FCE con el título Obra poética completa. 1967-2010 (2011).

Una breve aproximación a este aspecto puede verse en mi artículo "Poeta y divinidad. Aspectos de la mediación en la creación poética” (Badía Fumaz 2013).
} 


\section{LA RESPIRACIÓN EN LA OBRA DE ANTONIO COLINAS}

Dentro de esa estrecha relación entre palabra poética y cuerpo que insiste en vincular la creación con las funciones vitales, la importancia de la respiración en la obra poética de Colinas ha sido destacada por Luis Miguel Alonso (2000) y José Luis Puerto (1997), encontrando dos reflexiones fundamentales en el texto de José Enrique Martínez Fernández "Armonía y ritmo en Antonio Colinas: ajustes métricos en Noche más allá de la noche" (2004), donde su autor incide en el paralelismo ritmo-respiración y cómo el ritmo supone el criterio definitivo para reconocer la poesía verdadera, y en Luis Moliner, quien en el capítulo "Respirar (En torno a un verso de Antonio Colinas)" de su obra Respirar. La palabra poética de Antonio Colinas (2007) ha profundizado en el sentido que adquiere esta dimensión en sus versos ${ }^{4}$.

La dimensión biológica y orgánica de la respiración pone de relieve la importancia de la corporalidad, de los sentidos, en lo que atañe a la inspiración poética, idea aún novedosa para una contemporaneidad que cuando acepta la idea de inspiración la enclava en orígenes externos al hombre o muy internos a él, pero separados, en cualquier caso, de lo epidérmico, de lo palpable. Es tal la importancia de los sentidos que Colinas en su poesía va a desarrollar toda una serie de referencias paralelas a las de la respiración en torno al aroma como elemento de conexión entre lo interno y lo externo, lo inferior y lo superior ${ }^{5}$, motivo poético el del aroma que no tiene su correlato ensayístico. Estas referencias aparecen muy desarrolladas por ejemplo en el canto XXXV de Noche más allá de la noche, donde se reúnen en aspectos clave de la vinculación de la respiración con la creación poética que abordaré a continuación:

Me he sentado en el centro del bosque a respirar.

He respirado al lado del mar fuego de luz.

Lento respira el mundo en mi respiración.

En la noche respiro la noche de la noche.

Respira en labio el labio el aire enamorado.

Boca puesta en la boca cerrada de secretos,

\footnotetext{
Contiene esta obra, además del mencionado, los artículos, "El Regreso", "Variaciones sobre el centro" y "La palabra abierta ("Invierno tardío")", textos que se alejan ya del motivo de la respiración.

El aroma, el perfume, dota de realidad a la respiración invisible, la hace presente.
} 
respiro con la savia de los troncos talados, y como roca voy respirando el silencio, $\mathrm{y}$, como las raíces negras, respiro azul arriba en los ramajes de verdor rumoroso. Me he sentado a sentir cómo pasa en el cauce sombrío de mis venas toda la luz del mundo. $\mathrm{Y}$, al fin, yo era un gran sol de luz que respiraba. Pulmón el firmamento, contenido en mi pecho, que inspirando la luz va espirando la sombra, que renueva los días y desprende la noche, que inspirando la vida va espirando la muerte. Inspirar, espirar, respirar: la fusión de contrarios, el círculo de perfecta consciencia. Ebriedad de sentirse invadido por algo sin color ni sustancia, y verse derrotado en un mundo visible por esencia invisible.

Me he sentado en el centro del bosque a respirar. Me he sentado en el centro del mundo a respirar. Dormía sin soñar, mas soñaba profundo y, al despertar, mis labios musitaban despacio en la luz del aroma: "Aquel que lo conoce se ha callado y, quien habla, ya no lo ha conocido"

(Colinas, El río 343)

A grandes rasgos, puede decirse que Colinas establece unos lazos estrechos entre la inspiración y cierto tipo de respiración no ordinaria. Este peculiar modo de respirar aparece, a la manera de las tradiciones antiguas, vinculado con la sanación o, cuanto menos, con la posibilidad de una forma de vida más equilibrada y consciente. Ello conlleva que la inspiración poética, y por tanto la obra entendida desde la respiración se nos muestre como medio para lograr un estado armónico y no únicamente -que también-como fin en sí misma.

Es necesario recordar que para Colinas la respiración será un medio entre otros varios -meditación, contemplación, palabra poética, etc.- de alcanzar la armonía, casi siempre el fin último al que se orienta el poeta leonés. El dominio de la respiración, sin vincular ésta con la creación poética, será un motivo extensamente desarrollado en los diversos textos del autor. Sin embargo, en numerosas ocasiones la respiración también se considera como parte inseparable de la inspiración poética, tanto que en ocasiones la segunda se enraíza en la primera, justificando una detallada aproximación a este fenómeno. 
Ya se ha apuntado que la reflexión sobre la relación entre inspiración y respiración tiene lugar tanto en los textos poéticos como en los textos ensayísticos. Dentro de estos últimos, el lugar privilegiado para explorar el fenómeno de la respiración va a ser el conformado por el género particular, las "contemplaciones", que crea en sus Tres tratados de armonía, recipientes idóneos para un tipo concreto de reflexión, que constituyen su cauce más adecuado. Dada la aún mayor libertad de este medio, más todavía que la que puedan proporcionar las poéticas explícitas más ortodoxas, va a ser el medio en el que se va a analizar de una forma más creativa esta cuestión, dedicándosele, además de referencias constantes en los tres tratados, un capítulo exclusivo dentro del Tercer tratado de armonía, "Sobre el respirar", destacada esta palabra, por sus amplísimos significados condensados en el término, en letra cursiva.

Concibiéndose la respiración a partir de su fin último de consecución de equilibrio, la inspiración que deriva de ella adquiere ese mismo matiz teleológico. La inspiración, la palabra poética, está condicionada a la realización de ese fin último de la respiración, por lo que una vez alcanzado ese equilibrio -el estado de armonía- la respuesta más coherente es el silencio. Así sucede en la poesía de Colinas, donde por ello en ocasiones se apela al silencio como realización última de esa inspiración, en tanto se ha alcanzado ya el fin perseguido. La palabra poética ha cumplido su misión y por tanto debe desaparecer. Más que ese estado final, estudiado abundantemente por Luis Miguel Alonso (1990, 2000), aquí me interesa esa primera vinculación entre inspiración y respiración a la hora, sobre todo, del momento creador, y no tanto el espacio final similar o idéntico al que conducen ambas.

Dejando a un lado el estudio de la respiración como medio para lograr la armonía ${ }^{6}$, volvemos la mirada al estudio de la respiración dentro de la exploración de la teoría de la creación poética, en tanto que vinculada explícitamente por el salmantino con la inspiración literaria. El carácter subsidiario de la respiración queda de manifiesto cuando se la relaciona con los métodos orientales de lograr la armonía a través del dominio del cuerpo o con la tradición hesicasta del acceso al sentimiento religioso por medio

6 Esta vinculación da lugar a afirmaciones quizá aventuradas: “¿Cuál es la razón más poderosa para vivir? Sin duda, el respirar conscientemente. La respiración es uno de los escasísimos bienes que nos conducen gratuitamente a la armonía. Pero suele ser tanta nuestra diaria confusión que habitualmente ni siquiera somos conscientes de que respiramos" (Colinas, Tres tratados 23). 
de la oración del corazón, a la que volveré más adelante. En lo que ocupa a la inspiración, es un tipo de respiración particular la que va a propiciar esa inspiración, por un lado, y por otro va a establecer relaciones estructurales con ella mostrando paralelos en cuanto a su función o su orientación verticalhorizontal, entre otros aspectos.

Son escasos los textos en los que la psicología y la sociología en sus estudios sobre la creatividad, por no hablar de los estudios literarios, se han ocupado de la respiración. Ni siquiera en su asociación con el ritmo como vehículo de la creación ha sido explorada más que someramente, pese a ser la creatividad por el ritmo una constante en el testimonio de poetas, músicos y pintores. Sin embargo, cuando un autor reclama un lugar privilegiado para la respiración en su teoría de la creación poética, estudiar los contextos en los que ésta aparece y las implicaciones que tiene concebir la inspiración como vinculada a la respiración revela otros alcances más profundos; por ejemplo, puede actualizar la afirmación clásica grecolatina de la inspiración proveniente de factores externos ${ }^{7}$ entendiendo sus elementos de una manera más actual pero respetándose parte del esquema de la tradición.

"Inspirar, espirar, respirar, expirar... Dulces palabras que suenan muy cercanas, pero que se diferencian profundamente en su significación. Ellas fijan los límites del ser y del no ser, de la vida y la muerte" (Colinas, Tres tratados 310). Si acudimos a términos del campo semántico de la respiración, como la inspiración pero también espiración o aspiración, éstos aparecen relacionados, conectados con sugerencias afines:

- Inspiración: incorporar, movimiento hacia dentro.

- Espiración: ofrecer, desechar, devolver, movimiento hacia fuera.

- Respiración: reunión, ciclicidad, perpetuidad, reúne un doble movimiento hacia dentro y hacia fuera.

- Aspiración: tiende a lo superior, movimiento o actitud ascensional. Deseo.

- Expiración: no aparece. En realidad el sistema de la respiración que establece Colinas elimina esta posibilidad, pues el equilibrio dinámico

Frente a una concepción psicoanalítica donde la inspiración parte de la vivencia personal aunque ésta no sea consciente, la concepción junguiana de los arquetipos universales (ascendente en Jung, descendente siempre en Guénon), e incluso la psicología transpersonal, por la que Colinas se siente muy atraído. 
que sostiene todo y al que todo se reduce se alimenta también de la muerte, eliminando su sentido.

La articulación de la respiración, la formalización ordenada según el código del lenguaje pero también del poeta y del cosmos, es lo que en esta particular teoría creadora del poeta leonés da lugar al poema. Como señala Luis Moliner,

¿Qué puede ser el poema sino un aliento articulado, y articulado al aliento del cosmos, cuando la palabra poética ha sido verdaderamente respirada en el ritmo de esa elemental respiración? Pues la palabra, al respirarse, nos muestra su propia respiración, ésa que la ha producido, que la ha hecho posible. Y al caótico gruñido o a la desasosegada locuacidad ha de oponerse la palabra acordada. Palabra de nadie, tan neta y tan tenue, como silbo enamorado, casi sólo aire, música (26).

En palabras de Diego Doncel, Colinas nos presenta el "[h]iato trágico entre el hombre y el mundo" pues éste está exiliado en la otredad. Para superarlo, debe hacer consciente su unidad con el mundo, encarnado en la naturaleza, al que pertenece y donde se manifiesta "el ritmo verdadero de la vida". En un segundo momento, habrá que interiorizar esa realidad, respirándola (246 y 247). Pero, ¿qué es lo respirado? Se respira la palabra para incorporarla, pero no solo la palabra. El tratamiento gramatical de la respiración nos abre a otras interesantes implicaciones. En la poesía de Colinas, en ocasiones aparece el verbo respirar como intransitivo, pero con mayor frecuencia se utiliza éste como transitivo, añadiendo un objeto, lo respirado. Se respira entonces, además de la palabra, fuego de luz, noche, aire enamorado, azul, sombra, luz, vida o muerte, reforzando este recurso la idea de apropiación, de incorporación de la realidad externa al interior del poeta por medio de la función vital de la respiración:

Pulmón el firmamento, contenido en mi pecho, que inspirando la luz va espirando la sombra, que renueva los días y desprende la noche, que inspirando la vida va espirando la muerte (Colinas, El río 343).

Se refuerza con ello la idea de totalidad mencionada, no solo por la amplitud de lo respirado, sino por la participación del contexto y la integración de contrarios en esa respiración (luz / sombra, vida / muerte). Pues no solo el hombre respira algo, sino que respira en algo; incluso, la naturaleza, la realidad, ejerce también una respiración: "No era brisa, ni era viento. Era 
como una respiración que alentaba en el azul profundo, secreto, de cada cosa." (Colinas, Tres tratados 195). Todo lo real se anima por medio de la respiración, permitiendo la antropomorfización de la naturaleza -"pulmón el firmamento" - e identificación con el yo humano ${ }^{8}$.

¿Pero es, en efecto, lo respirado lo que fecunda al poeta o es el propio movimiento de la respiración? Esta pregunta plantea implicaciones directas en la teoría de la creación poética de Colinas, pues si la relevancia recae en lo respirado estaríamos ante una concepción clásica de la inspiración, de carácter externo, de movimiento descendente y con la participación de un sujeto pasivo. Si hacemos, en cambio, énfasis en el movimiento de la respiración, de la incorporación, del acordamiento, el yo poético será el que sustente el proceso de la creación aun manteniendo un vínculo con lo externo, lo respirado.

La tendencia a conjugar en equilibrio dos posturas extremas, la inspiración exclusivamente externa o el trabajo único del poeta encarnado en el esfuerzo de la respiración, se traduce también aquí en una solución de compromiso a medio camino entre las dos propuestas. El movimiento descendente de la inspiración debe ser acogido en un poeta acordado con ella en la respiración, solución que recuerda al intento de Fernando de Herrera de conjugar la idea de genio con la de Dios en las Anotaciones a la poesía de Garcilaso, proponiendo un encuentro entre el genio ascendente y la divinidad descendente:

No erraría mucho quien pensase que el entendimiento agente de Aristóteles es el mismo que el genio platónico. Es él quien se ofrece a los genios divinos y se mete dentro, para que descubran con su luz las intelecciones de las cosas secretas que escriben. Y sucede muchas vezes que, resfriándose después aquel calor celeste en los escritores, ellos mismos, o admiren o no conoscan sus mesmas cosas, $\mathrm{i}$ alguna

8 El ritmo proviene de lo natural. Tanto de lo interno al hombre como de lo externo. Por ello, poetizar es también acordar con palabras el ritmo interior con el ritmo exterior. Sin embargo, ese ritmo exterior que se encontraba en los orígenes míticos del mundo o en espacios armónicos, apunta Colinas, ha ido desapareciendo. Antes, "sin saberlo -puesto que aún no peligraba- el ser humano habitaba un microcosmos equilibrado del que se nutría, y cualquier tipo de transformación que en él se diera estaba fundamentada en la no agresión al medio natural, es decir, en lo rítmico, en lo climático, en lo pausado, en lo cíclico, en lo estacional" (Colinas, Sobre la vida 187). 
vez no las entiendan en aquella razón a la cual fueron enderezadas y dictadas del (Fernando de Herrera cit. en Roses Lozano 35).

Esta postura intermedia concuerda mucho más con el pensamiento desarrollado por Colinas, al exigir la participación necesaria de un elemento externo al poeta pero a la vez la disposición y el trabajo del individuo: la creación exitosa solo tiene lugar cuando ambas instancias concuerdan.

En el planteamiento de Colinas, esa sustancia externa, como natural o divina, en cualquier caso ajena y autónoma al hombre, debe ser permanente, teniendo una presencia continua, sea o no reclamada por el poeta, con lo que el movimiento primero debe partir de éste a partir de un cierto estado de ánimo especial. No se reconoce entonces fácilmente la musa clásica que se inclina sobre el hombro del poeta y le susurra los versos, sino la coincidencia necesaria entre un primer momento de inspiración y la particular disposición de ánimo del autor que se abre a aquélla.

\section{RESPIRACIÓN COMO REUNIÓN. DINAMICIDAD DE LA RESPIRACIÓN}

La idea de la respiración como fenómeno global que atañe no solo al hombre sino a otras instancias de la realidad, fundamentalmente a la naturaleza, remite explícitamente en la obra de Colinas a la distinción entre macrocosmo y microcosmo, distinción que desaparece precisamente por medio del proceso unitivo de la respiración: "Estrujar con la mano un puñado de frescas hojas de eucalipto y aspirar plácidamente su perfume: fundir durante unos instantes -mientras el perfume dura- el microcosmo de la hoja con el macrocosmo de nuestros pulmones" (Colinas, Tres tratados 44). En la respiración se salva la escisión trágica entre hombre y naturaleza, pero no a costa de producirse una amalgama entre el yo y lo otro sino a partir de la imagen dinámica -la dinamicidad de la respiración es clara: respirar es incorporar lo externo, que nos recorre y es devuelto luego al exterior-del círculo, de la reconciliación más que de la identificación: "Inspirar, espirar, respirar: la fusión / de contrarios, el círculo de perfecta consciencia" (Colinas, El río 343); "Respirando esta luz fría el espíritu se reconcilia con el cuerpo y el cuerpo con el mundo. Es la suprema Unidad" (Colinas, Tres tratados 61).

La dinamicidad de estas imágenes sí refuerza, por el contrario, un aspecto del poeta inspirado clásico: la apertura interior del poeta que permite que el 
aliento inspirador transite por él, lo recorra, y sea devuelto, ya formalizado, al exterior. El poeta debe buscar en este estado un equilibrio armónico dinámico, pues el estatismo absoluto -la imagen del poeta cáscara que nos devuelve la tradición- no tiene lugar en el pensamiento contemporáneo, salvo que lo equiparemos a determinados estados de conciencia enajenados, alterados (locura, mística o hipnosis, por ejemplo).

La respiración se muestra como un símbolo cíclico, un símbolo del movimiento -y por tanto un símbolo vital-y de la conexión entre lo interior y lo exterior en un plano horizontal. Pero fácilmente se percibe también como un eje vertical, en realidad un eje con dos puntas superiores coincidentes, pues el movimiento de la respiración es tal que el aire se introduce desde arriba, desciende y se difunde, y vuelve a ascender para ser expulsado por el mismo conducto. Este descenso-ascenso es continuo; si acaso pueden verse dos instantes de un equilibrio en tensión: cuando el aire está dentro y cuando está fuera (abajo-arriba) ${ }^{9}$. Coincide lo superior con lo exterior y lo inferior con lo interior. La idea de inspiración poética que puede traslucirse toma lo poético como algo que atraviesa al poeta pero ha de ser devuelto a su origen. En este sentido, lo inspirado - que fecunda lo poético- no sería propiamente humano, sino que el hombre lo tomaría para devolverlo continuamente, de una forma y con un fin fecundante. En ese proceso el aire se altera, momento equivalente al trabajo técnico realizado por el poeta, y lo que se devuelve no es ya propiamente la inspiración pero tampoco algo exclusivamente individual: es la obra poética compartida.

La simbólica disposición corporal vertical de la respiración es fácil de conectar con la idea clásica de inspiración. El propio Colinas afirma esta verticalidad a partir de las enseñanzas del Tao: "La necesidad de 'respirar desde los talones' a la que aludió el taoísta Chuang Zu. Desde los pies comienza a fluir la energía que asciende. En ellos comienza la 'órbita macrocósmica', la que asciende por la espalda a la nuca y luego desciende de la frente a los pies. Por eso, los talones deben ser los primeros en respirar (Tres tratados 305). Este eje vertical es fácil de conectar con la idea occidental tradicional de la inspiración, pero también con el pensamiento de Carl Gustav Jung, de

$9 \quad$ Luis Moliner ve este momento suspendido entre inspiración y espiración de este modo: "Y el ritmo, en su movimiento, alberga el reposo, ese punto muerto necesario para que la vida no cese y que se abre en el intervalo entre la inspiración y la respiración" (41). Dos momentos respectivos en los que primero el uno contiene el todo y después el uno sale de sí para fundirse con el todo. 
clara influencia en el pensamiento de Colinas, o René Guénon. Más que un movimiento de subida y bajada, se corresponde de manera más exacta con un movimiento circular vertical, donde cabe la posibilidad del cambio, no siendo igual lo que baja que lo que sube.

La cita señalada introduce una nueva dimensión en la reflexión sobre respiración e inspiración en Colinas. En ella se dice que la respiración se inicia en los talones, es decir, en el punto más bajo del eje vertical, para ascender y luego retornar en el descenso. Se establece un doble movimiento, entonces, en el momento de atracción del aire exterior: uno que se inicia de abajo hacia arriba y, de forma paralela, otro que comienza de arriba hacia abajo. La confluencia de estos dos movimientos no puede tener otro lugar que el corazón, el centro simbólico donde confluyen las dos ruedas de inspiración, conjugándose perfectamente el planteamiento descendente clásico con el planteamiento ascensional de, por ejemplo, el psicoanálisis.

Sin alejarnos mucho de los planteamientos psicoanalísticos, fundamentalmente desde la perspectiva de C. G. Jung, desde el punto de vista de la creación poética es interesante percibir la dimensión de la respiración como actividad común, no solo porque corresponde a cada individuo sino porque todos comparten el mismo aire respirado. Se constituye entonces a partir de la insistencia en la respiración una fuente común para la inspiración, que ya no se vincula con un dios superior sino con la materia de la divinidad natural, cotidiana. En consecuencia, el poeta no es un ser escogido sino que pasa a comprenderse como un iniciado.

\section{LAZOS CON EL PENSAMIENTO TRADICIONAL}

Varias referencias mencionadas por Colinas en sus ensayos vinculan sus ideas sobre la inspiración con el pensamiento tradicional, sobre todo con aquél que tiene su raíz en Oriente -hinduismo, budismo, taoísmo-, aunque la conexión entre palabra y corporalidad remite asimismo al hesicasmo, doctrina del cristianismo oriental, y su influencia a partir de la Filocalia y Relatos de un peregrino ruso.

La vinculación con el Tao es la que Colinas señala con mayor frecuencia, como puede verse en las siguientes líneas de Tres tratados de armonía: "Me asalta uno de esos momentos inevitables de vacío y de falta de esperanza. Voy al bosque. Allí, sentado, respiro plácidamente y repito muy despacio 
una de las claras sentencias del Tao. Cuando regreso a casa todo el malestar ha desaparecido" (134). No obstante, no solo se apunta brevemente la correspondencia entre respiración y Tao, recurrente también en su obra poética $^{10}$, sino que ésta se desarrolla en alguno de los volúmenes puramente ensayísticos:

Más allá de una concepción evasiva o trascendentalista de la existencia, el ser humano antes vivía en función de que respiraba. Sabemos que todo el pensamiento primitivo oriental -hinduismo, budismo, taoísmo- tenía por fin esa meta: la de que el ser humano no es, en esencia, sino algo que respira correctamente y, al hacerlo, vive sanamente, en equilibrio. Y que de ello es consciente. Más allá del rito y de la plegaria del hombre religioso, o del orden mental del pensador sistemático, el ser humano es persona sintiente que respira. También en ese respirar -es decir, en ese sutil y decisivo cambio de energías y de alientos- se basa la vida humana [...]. Por tanto, en el fondo, uno es, y siente, y razona, en la medida en que respira, en que lo hace correctamente y, al hacerlo, vive en equilibrio y en plenitud" (Colinas, Sobre la vida 196).

Sin embargo, este equilibrio dinámico, pese a ser idóneo para el desarrollo vital del hombre, no propicia la creación artística. Para que ésta fructifique, ese equilibrio debe estar incompleto o en peligro; esa imperfección es lo que mueve a la creación. Sugiere René Passeron en Le naissance d'Icare que si es difícil ver qué pasos da el creador para llegar a serlo, quizá se pueda, abordando de forma indirecta la cuestión, ver qué pasos da para dejar de serlo o fracasar en su proyecto de creación (27). En Antonio Colinas, el despojamiento hacia el silencio conlleva el abandono de la escritura, de igual modo que el paso del sentimiento a la razón mueve al autor literario de la poesía a la reflexión, indica el leonés. En consecuencia, dentro de un estado totalmente armónico no habrá espacio para la creación poética. Habiendo cumplido la respiración su función última, elimina en su culminación la palabra. Como elemento incitador de la palabra poética, no puede, paradójicamente, tener un éxito completo para poder permitir la emergencia de la creación, pues teniéndolo la palabra desaparece. Es por ello que, desde esta perspectiva

$10 \quad$ Ver por ejemplo: “Cuando Todo es Uno / y cuando Uno es Todo, / cuando llega la hora interior, / se inspira la luz / y se espira una lumbre gozosa. / Entonces, amor se inflama / y oímos los silencios de fuego" (Colinas, El río 494). 
del análisis de lo no logrado, la creación surge en un estado de desarmonía; el ruido, la inestabilidad en el interior del poeta es lo que permite, lo que mueve a, la creación.

Si el poeta culmina su obra y abandona la palabra al llegar al equilibrio, igual que el místico abandona la palabra -que es camino-al alcanzar su meta, la creación se origina por el desequilibrio, lo dispar, lo múltiple diferente, lo discordante, a lo que se trata de imponer una coherencia. Si el acuerdo llega con la respiración que equilibra la relación entre dentro y fuera, arriba y abajo, macrocosmo y microcosmo, la creación poética ha partido necesariamente de una excesiva presencia de uno de los dos polos. Por medio de la respiración o por medio de la palabra respirada / inspirada el poeta logra su homeostasis, pero para poder crear debe estar en constante búsqueda de equilibrio, en compensación cambiante, pues el equilibrio conduce en el pensamiento de Colinas al silencio, a la renuncia a la creación que se aparece ya como innecesaria habiéndose logrado su fin último ${ }^{11}$. La autorregulación por medio de la respiración termina por anular la creación, pues para que haya novedad debe existir desequilibrio.

Esta concepción de la poesía la enclava en la anormalidad, el desequilibrio, como medio para lograr la armonía, concepto fundamental en la poética de Colinas. Por lo tanto, este aspecto confirma otra vez la función teleológica de la poesía en el autor leonés, por lo menos desde su formulación teórica. La palabra respirada o la palabra inspirada -la palabra poética- es la vía para alcanzar el fin ansiado por el poeta a partir de planteamientos de herencia taoísta, como ejemplifican las siguientes líneas de El sentido primero de la palabra poética:

Nos acordamos con el Todo respirando la palabra, respirando rítmicamente, musicalmente. Y nos acordamos con el Todo cuando estamos inspirados. Y el que respira musicalmente con el verso respira infinito, funde los extremos. [...] En definitiva, respirando

11 Se nos revela aquí de nuevo la vinculación entre creación y sanación del hombre, entre creación y autorrealización. No parece haber espacio para la creación en el hombre completo. Sin embargo, debe advertirse la evolución poética en Colinas, que, pese a cerrar varios poemarios con una renuncia a la palabra no llega a abandonar definitivamente la escritura. Por lo demás, otras funciones del hecho literario son reclamadas en diferentes textos, como el conocimiento, la absorción de mundos, incluso la comunicación de un pensamiento inspirado. 
con el ritmo del verso - del poema- existimos en el más alto grado de consciencia, sanamos y buscamos la liberación (33).

La interiorización hasta el punto de la inconsciencia de la respiración y su vinculación con la palabra, en uno u otro sentido, además de la orientación hacia un fin armónico propugnado por el taoísmo, vincula la propuesta de Colinas con la tradición hesicasta. Pese a que no encontramos una reflexión explícita sobre ello en sus ensayos, sí se constata el conocimiento de dos obras fundamentales, la Filocalia y Relatos de un peregrino ruso: "Ambos libros [se refiere a La pequeña crónica de Ana Magdalena Bach y Relatos de un peregrino ruso] son inconfundiblemente personales, aunque reconozcamos en ellos sus fuentes literarias: los místicos del Hesicasmo, los textos de la Filocalia, y por supuesto la Biblia, la luterana de Bach o la ortodoxa del peregrino" (Colinas, Tres tratados 271).

La relación entre respiración, palabra poética y oración se concentra en una sentencia de Thomas Merton señalada por Colinas, "Vivir es orar respirando" (Tres tratados 175), que permite introducir la inextricable vinculación de la palabra con las funciones vitales tanto de la respiración como de los latidos del corazón, funciones ambas que se acompasan idealmente con la palabra en el hesicasmo. Por esta razón se alude al método de oración hesicasta como oración del corazón, pues se construye sobre la repetición e interiorización de la secuencia "Señor Jesucristo, Hijo de Dios, ten piedad de mí, pecador", aunque existen otras variantes, de tal manera que pueda llegar a ligarse a las funciones vitales ${ }^{12} \mathrm{y}$ repetirse inconscientemente armonizada con ellas, siendo también conocida como oración de Jesús ${ }^{13}$.

12 La vinculación de la oración con la respiración y con el latido aparece explicada por Nicéforo el Solitario en la Filocalia: "Tú sabes que nuestro soplo, el aire de nuestra inspiración, nosotros no lo espiramos a causa de nuestro corazón. Pues el corazón es el principio de la vida y del calor del cuerpo. El corazón atrae el soplo para rechazar su propio calor hacia afuera mediante la espiración y asegurarse así una temperatura ideal. El principio de esta organización, o mejor su instrumento, es el pulmón. Fabricado por el Creador de un tejido tenue, introduce y expulsa el aire sin detenerse, a la manera de un fuelle. De ese modo el corazón, atrayendo por una parte el frío mediante el soplo y rechazando el calor, conserva inalterablemente la función que le ha sido asignada en el equilibrio del ser vivo" (155).

13 Tal como aparece explicada en Relatos de un peregrino ruso, la oración del corazón se realiza de la siguiente manera: "cuando te hayas habituado a esta actividad, comienza a introducir en tu corazón la oración de Jesús, y al hacerla salir al mismo tiempo que la respiración, es decir, al aspirar el aire, di o piensa: 'Señor Jesucristo', y al expirarlo: ‘¡ten piedad de mí!’” (105). 


\section{RITMO Y RESPIRACIÓN}

"El verso es la palabra originaria, fundadora; palabra que reproduce el ritmo del mundo. Por eso, al leer el verso, al respirar las palabras, respiramos el ritmo y la música del mundo. Y nuestro pecho se inflama entonces de eternidad musical", señala el poeta leonés en Tres tratados de armonía (Colinas, Tres tratados 39). Y es que desde su misma constitución la respiración está vinculada al ritmo y el ritmo es la base de la creación, no solo en la formalización del poema sino también en su propiciación, en el momento más propio de la inspiración poética en el que podemos recordar, por ejemplo, a un Antonio Machado caminando y componiendo al ritmo de sus pasos. Ese movimiento rítmico y binario de la respiración es el mismo movimiento rítmico y binario del caminar.

Esta cualidad binaria no es disgregadora sino, como se ha tratado de exponer, integradora, pues dos movimientos contrapuestos -dentro/fuera-se alternan y conjugan en un acto único, completo. Así debe entenderse la creación para Antonio Colinas, en términos de movimiento, un movimiento con sentidos contrarios pero que relaciona los mismos en una entidad superior, diferente.

A partir del ritmo se puede construir, entonces, una teoría de la inspiración sobre la respiración, inspiración concebida no como una entidad evasiva tal como lo entiende la contemporaneidad, advierte Colinas, sino apegada "al ritmo, otra de las claves más decisivas del espíritu mediterráneo. El ritmo que la respiración propaga y que los monjes hesiquiastas reciben no sé de qué remotas fuentes orientales" (Del pensamiento I, 61).

Emparentada conceptualmente con la propuesta de Colinas, el poeta Carlos Sahagún desarrolla una idea del momento de creación poética basada en el ritmo. El origen del poema, afirma, no se encuentra en la razón o en la voluntad, sino que tiene un carácter espontáneo. Surge según este poeta a partir de una vaguedad y dispersión previas, estado de "confusión" lo ha llamado Colinas, siendo concretado a partir del surgimiento del ritmo, cuya formalización, ahora sí, debe contar con la voluntad y la conciencia. Luego,

[e]ncontrar esa forma de expresión adecuada no es, desde luego, una tarea del todo automática. En algunos casos el esquema rítmico hallará sin esfuerzo su configuración fónica y de sentido (son los poemas de gestación momentánea). En otros, el poeta no encontrará las palabras precisas y tendrá que ir dejando lagunas a lo largo del poema. [...] La voluntad intervendrá luego corrigiendo y revisando 
esos fragmentos, si no han logrado ser expresión exacta de nuestras vivencias (Sahagún 197-198).

Ese ritmo para Colinas -también para Sahagún-hunde sus raíces en la música del mundo y la música del ser, siendo entonces la poesía "palabra ritmada, palabra en armonía y palabra que se respira" (Colinas, El sentido 326), ritmo "de la palabra que se aspira y que inspira" (Colinas, Del pensamiento I, 226).

La vinculación de la respiración y la creación por el ritmo aparece también en poetas fuertemente "materiales". Como afirma Pablo Neruda en una entrevista a Antonio Colinas, la vinculación cuerpo-poema conduce a una relación entre los ritmos biológicos y los propiamente poéticos, determinando no solo el proceso creativo sino el objeto artístico que de él resulta. Dice Neruda:

Mis formas verbales - cuando he tenido tiempo de hacerlo- las he visto reflexivamente y me parece que tienen mucho que ver con mi propio organismo, con mi temperamento, diferente en cada temporada y en cada día, y hasta con mi propia respiración. La forma poética tiene mucho que ver con la respiración, y además con el ambiente en que se desarrolla, con la atmósfera y con todo" (cit. en Colinas, El sentido 351-352).

La respiración no solo podemos relacionarla con la inspiración, sino que determina, entonces, la forma poética. En tanto la respiración tiene que ver con el ritmo, y también con los procesos biológicos, va a apelar a la forma, a lo material. Esto nos lleva más allá de la consideración inmaterial de la inspiración, aunque la inspiración haya estado ligada desde su origen a la forma (recordemos a Platón o a Coleridge, con su defensa de que el poema se hace presente en su forma, no recibiéndose la idea del poema sino el poema en su formalización lingüística). Señala asimismo Neruda algo de lo que participa Colinas: el estado de ánimo particular del poeta y el espacio de la creación mantienen una relación inmediata con el poema.

En sus aspectos formales, la correspondencia entre la respiración inspiradora y la materialidad de la escritura se deja notar en la primera etapa de su producción poética en la abundancia de versos largos, amplios, autoconclusivos, por ser asimismo la respiración amplia, serena, profunda, armónica. Los versos cortos y con pausas de etapas posteriores no mantienen esta relación estructural con la respiración en el dominio del verso, pero sí en el de la estrofa, constituyéndose oposiciones que resuelven en la materia poética el fenómeno binario y rítmico de la respiración. El camino seguido 
por el poeta hacia un mayor esencialismo, una poesía del silencio que abandona progresivamente los versos extensos y los poemas largos, supone otro ejemplo de cómo en la obra de Colinas la práctica poética va variando pero permanece fiel a un pensamiento sostenido recogido en sus ensayos y poéticas explícitas, respecto del que se percibe siempre una correspondencia.

La amplitud del aliento poético que se percibe en los versos extensos del poeta recuerda en efecto a los poetas fuertemente materiales Pablo Neruda y Walt Whitman, pudiéndose encontrar también resonancias de otros contemporáneos españoles como Claudio Rodríguez. Señala Guy Merlin Nana Tadoun en su libro Antonio Colinas y la escritura como aventura circular una probable referencia del canto XXV de Noche más allá de la noche, cuyos versos he citado anteriormente ("Pulmón el firmamento, contenido en mi pecho...") a los versos escritos por el zamorano en el poema titulado "A la respiración en la llanura” de su libro Conjuros (220): “¡Dejad de respirar y que os respire / la tierra, que os incendie en sus pulmones / maravillosos! [...] Tened calma / los que me respiráis, hombres y cosas. / Soy vuestro. Sois también vosotros míos. / [...] Cómo aumentan las rosas / su juventud al entregarse. ¡Abríos / a todo! El heno estalla en primavera, / el pino da salud con su olor fuerte. / ¿Qué hostia la del aliento, qué manera / de crear, qué taller claro de muerte!" (Rodríguez, Alto jornal 46-47). Pese a que este ejemplo de intertextualidad abre interesantes perspectivas, me limitaré a destacar cómo las ideas del universo que respira, del hombre respirado y de la comunión de lo creado en la respiración son compartidas por ambos poetas. El ritmo que ordena el ciclo de la creación queda patente en la exclamación final: "iQué hostia la del aliento, qué manera / de crear, qué taller claro de muerte!”.

La relación entre respiración y creación poética, así como la influencia de la respiración en la formalización del verso, se percibe en otros poetas contemporáneos. En José Ángel Valente, por ejemplo, asistimos a una respiración apegada a la materia, paralela al ritmo del latido, que se comprende dentro del proceso de creación poética como un espacio de conexión de lo interno con lo externo, sin eludir tampoco esa vinculación reiterada en la tradición a la luz: "La luz es alta y pura para cuanto respira", leemos en el poema "La mañana” de Poemas a Lázaro (Valente, El fulgor 46). Por el contrario, las constantes referencias a la respiración del chileno Gonzalo Rojas, también premio Reina Sofía de Poesía Iberoamericana (1992), pese a mantener la conexión fisiológica de la misma con el fenómeno de la creación, se resuelven 
en el aliento entrecortado, en la asfixia, en el reconocimiento-fecundo- de la oposición entre respiración y vida ${ }^{14}$.

\section{RESPIRACIÓN Y PALABRA POÉTICA}

El carácter binario pero integrador de la respiración se despliega, trasladado al proceso de creación poética, en las siguientes oposiciones:

- consciente / inconsciente

- razón / emoción

- fuerzas sociales / individuales

- partes del hombre eternas / partes históricas

- deseo de individualidad / deseo de fusión con el cosmos

La tensión entre los dos polos que surge de la confrontación de dos elementos en los binomios anteriores se resuelve por medio de la respiración: "Cuerpo y psique, materia y espíritu, son una misma cosa en el instante de la respiración plena. Entonces, no existen los desequilibrios, que sólo brotan del predominio de uno o de la otra" (Colinas, Tres tratados 308).

El proceso de respiración vinculado con la inspiración aparece, por lo demás, también en la recepción de la obra poética al concebirse ésta como palabra que se inspira y que inspira. Así la palabra inspirada lo es en una doble dirección, por un lado en tanto que concebida con intervención de la inspiración, y, por otro, en tanto que ella misma es palabra inspiradora. Entendida de este modo, la inspiración remite a la clásica cadena imantada que plantea Platón en el Ión, donde lo poético se transmite por medio de la palabra a su receptor a través del poeta.

14 Para comprender la dimensión armónica de la respiración en Colinas frente a otras manifestaciones poéticas contemporáneas pueden verse los poemas de Gonzalo Rojas "Ejercicio respiratorio" ("Azar / con balbuceo son las líneas de Ilión / en las que está escrito el Mundo, con / balbuceo y tartamudeo y / asfixia, el oleaje / de las barcas exige ritmo, Homero / vio a Dios", Concierto 106) y "La palabra" ("Un aire, un aire, un aire, / un aire, / un aire nuevo: / no para respirarlo / sino para vivirlo", Concierto 98). La distancia entre ambas formas de concebir la respiración en relación con la creación y su correspondiente realización formal en el poema es patente. 
El poema verdadero, afirma Colinas recordando la sentencia de Emily Dickinson, respira (Tres tratados 25) ${ }^{15}$. Mundo, poeta, alma ${ }^{16}$, poema, palabra y lector respiran en esta concepción de la creación tan estrechamente vinculada a una finalidad particular, la de lograr un estado armónico por medio de la respiración directa o por medio de la respiración en la palabra. Concepción en la que, en palabras de José Luis Puerto, la respiración como fenómeno físico trasciende a pesar de ello el orden de lo físico "como elemento que nos relaciona con el ritmo del mundo y con la armonía, con el 'orden celeste'; como elemento que nos sitúa en el centro del mundo" (64).

Colinas juega en toda su obra con la dualidad que se establece entre lo visible y lo invisible, o más propiamente, lo perceptible y lo imperceptible. La búsqueda de concreción emerge en no pocas ocasiones. De ese modo, la percepción sensorial más propia de sus primeros poemarios (Preludios a una noche total, Truenos y flautas en un templo, Sepulcro en Tarquinia, etc.) vuelve a surgir en momentos concretos de su obra posterior. En lo que atañe a la respiración, esta voluntad de apropiación fenomenológica del mundo, de percepción sensitiva, dota de consistencia al fenómeno originalmente "transparente" de la respiración por medio del aroma, del perfume del mundo.

El aroma será entonces el modo en el que la respiración, lo respirado, se encarna, adquiere presencia palpable, dentro de una cosmovisión donde la visión no aparece como órgano privilegiado, sino que su lugar es sustituido por el olfato, el tacto y el oído ${ }^{17}$ : "Escucho el corazón del pinar que gotea / sonámbulo en su espacio de silencio y aroma" (Colinas, El río 213). Es por ello que los espacios de la respiración serán, como se aprecia en el ejemplo, a menudo coincidentes con los espacios de la inspiración poética, destacando el bosque, el jardín o los lugares con presencia de agua, verdaderos lugares de la inspiración en la tradición nuestra.

$15 \quad$ Y también: "La palabra que se respira al pronunciarla. La palabra acordada con la respiración, sumida en el ritmo que imponen los pulmones y el mundo, que ya es sólo música: la palabra en el verso" (Colinas, Tres tratados 311).

16 "La palabra en armonía es la respiración del alma" (Colinas, Tres tratados 313).

17 Juhani Pallasma subvierte la importancia tradicional de la visión a partir de la lectura que realiza de los fenomenólogos, sobre todo de Merlau-Ponty, señalando que "[1]a visión revela lo que el tacto ya conoce. Podríamos pensar en el sentido del tacto como en el inconsciente de la vista" (53). La percepción no visual del mundo es previa a su conocimiento por medio de la vista, que supone siempre una distancia con lo conocido que otros sentidos corporales no imponen. 
El perfume dota de realidad a la respiración invisible, la hace presente. Pero, por otro lado, mantiene el esquema de la respiración que he indicado: es ascensional, proviene de abajo, de la materia; replica el eje vertical ya aludido. Sin embargo, se orienta hacia una cierta horizontalidad en tanto que su origen es la materia, siendo entonces una inspiración inferior, desde abajo, desde la horizontalidad del hombre en el mundo. "Como vasos repletos derramaban las hojas / el agua verdeazul y de la tierra parda / ascendía un aroma refrescante, profundo" (El río 53), escribe Colinas, estableciendo una inspiración ya no exclusiva de la divinidad vertical sino de una concepción más panteísta del fenómeno.

La dimensión conectiva de la respiración que simboliza la unión del comienzo y del fin, la vitalidad en su repetición, cristaliza en la mezcla de aromas de un espacio concreto probablemente en el noroeste español:

Aroma de la jara y aroma de la encina
se mezclan en mi sangre desde tiempos remotos.[...]
Luz y sombra del límite, aroma de la jara
y aroma de la encina mezclando en nuestra sangre
el ocaso y la aurora, la infancia con la muerte,
el sueño con la carne estrellada en la piedra
de limitadas noches, de noches infinitas (Colinas, El río 339).

La mezcla de aromas, el de la jara y el de la encina, une los opuestos, resume la trayectoria vital del hombre. Pero, a la vez, el aroma al mismo tiempo arcano e intolerablemente presente permite la manifestación de la divinidad, la comunicación de lo divino por medio del aroma: "Habla, diosa, a través de las hojas del encinar, / enciéndeme, envía tu embriaguez, / arráncale a las ásperas ramas / todo el perfume, su estrellada fiebre" (Colinas, El río 385). La enajenación o irracionalidad de la inspiración queda patente también en estos versos.

Uno de los ejemplos más explícitos de esta relación entre inspiración y respiración aparece en el poema La muerte de Armonía (1990), libreto operístico que puede leerse como un poema largo, concebido como significativo homenaje a la filósofa María Zambrano:

Respirar la palabra como el pecho respiró aquel aroma de la infancia, como suena en oído manantial, como mano de padre va y se posa en la mano del hijo que se abisma. 


\begin{abstract}
Respirar la palabra como aroma.
El verso dicho es verso respirado.

Inflamación la música del verso

en pecho y sangre que nos diviniza (Colinas, El río 425).
\end{abstract}

La palabra ha de penetrar en uno pero exige a su vez su manifestación. La creación no puede entonces ser tan solo inspiración, recepción pasiva de aquello que viene dado, sino que debe ser devuelta en un ciclo rítmico que ordena el mundo. Para Colinas, este proceso diviniza al hombre.

Sin embargo, la palabra poética no siempre tendrá para el poeta leonés la fuerza suficiente para conducir al hombre a la plenitud. Dos son los significados que la ausencia de palabra, el silencio, despliega en la obra del autor: un silencio inicial, previo muchas veces a la palabra, un silencio vacío en definitiva, y un silencio pleno, aquél que viene tras la palabra, aquel que hace innecesaria la palabra pues aparece después de la búsqueda. Estos dos silencios son los que dan sentido a los versos siguientes: "Respiraba silencios, / pero no respiraba. / Mas hoy es el silencio / el que a mí me respira" (Colinas, El río 656). La palabra como medio debe entonces abandonarse cuando ha cumplido su función, para no convertirse en elemento fosilizador del hombre:

Casi todas las cosas, desde hoy, serán más bellas sin esa cadena

de la palabra que define y ata, y que, a veces, hasta ocupaba el aire que respirar no puedo (Colinas, El río 658).

\title{
7. CONCLUSIÓN
}

Dentro de la concepción teleológica que Antonio Colinas tiene de la literatura, la palabra poética tiende su afán hacia el fin concreto de la consecución de la plenitud del hombre. La poesía se convierte entonces en herramienta sanadora para aquél que la escribe y también para aquél que la lee, compartiendo lugar, en consecuencia, con otras actividades que tienden hacia el mismo fin, como la contemplación o la espiritualidad. Común a estas tres formas de lograr la vivencia armónica con el mundo aparece el ejercicio controlado de la respiración, emergiendo el ritmo como elemento que conjuga el interior del hombre con los fenómenos naturales externos a él. En este trabajo he querido mostrar cómo la palabra poética surge para Colinas en estrecha relación 
con la respiración, no solo en el paralelismo rítmico mencionado sino en el mismo proceso de la génesis poética. La respiración permite, favorece, la inspiración artística.

La tradición, desde el propio sentido etimológico de la palabra inspiración hasta las diversas formas de creación por el aliento divino que pueblan el pensamiento occidental, sirve de sostén a la propuesta del poeta leonés, quien apela una y otra vez a la tradición occidental pero también oriental para sostener la conexión entre respiración y palabra poética.

Esta relación se inserta en el ámbito más amplio de la plenitud, de la armonía con el universo. Es por ello que no resulta chocante la representación del ser, de la acción de ser plenamente, por medio de sensaciones físicas, corporales: el aroma o la percepción física, olfativa, táctil del entorno son medios privilegiados de conectar con el mundo. Dentro de este ámbito, la creación poética se convierte a la vez en un medio y en un producto. La palabra surge del ritmo intrínseco al mundo y al hombre, pero a la vez refuerza por medio del ritmo esa conexión entre macrocosmo y microcosmo oculta en ocasiones para Colinas al hombre moderno.

Sin embargo, hemos apuntado cómo al ser un medio la palabra se convierte en ocasiones en un escollo o por lo menos en un estadio intermedio prescindible. Se impone en esos momentos el abandono de la palabra, la vivencia directa de la plenitud donde el discurso racional o emocional solo puede interponer una innecesaria distancia: aparece entonces en la poesía de Colinas el tópico acerca del silencio final, la voluntad última de abandonar la palabra poética para entregarse simplemente a la vida: "Nada debe turbar tu pensamiento, nada / turbar tu corazón. Respirar y existir [...]. Adiós a la palabra, escoria de la luz" (El río 344).

El estudio del motivo de la respiración, en definitiva, ordena la teoría literaria del poeta leonés. Su relación con las ideas clásicas de la inspiración poética, la evidencia de una materialidad casi fisiológica de la creación, su función como símbolo de una poesía entendida como elemento unitivo y medio de alcanzar la armonía, la relación con el silencio y la ausencia de palabra, su carácter eminentemente rítmico o la incorporación del mundo en el yo por medio de la respiración y la palabra son hitos que hemos podido ir recorriendo en este trabajo.

Por otro lado, la riqueza de la reflexión del poeta leonés tanto en su obra poética como ensayística tiende numerosas conexiones hacia una tradición, la que conecta la creación poética con la respiración, en la que no he podido profundizar en estas páginas. Sirvan por ello como pequeña muestra, para 
terminar, dos citas recogidas por Colinas en sus ensayos. La primera, de Ernest Jones: "Las funciones respiratorias son el núcleo de la inspiración en su sentido literal" (cit. en Colinas, Tres tratados 71). La segunda, de Arquíloco: "Aliento mío (...) entiende que es un ritmo el vivir" (cit. en Colinas, Un tiempo 34).

\section{BIBLIOGRAFÍA}

Alonso Gutiérrez, Luis Miguel. El corazón desmemoriado. Claves poéticas de Antonio Colinas. León: Diputación de León, 1990. Antonio Colinas, un clásico del siglo XXI. León: Universidad de León, 2000.

Badía Fumaz, Rocío. "Poeta y divinidad. Aspectos de la mediación en la creación poética". El genio maligno 13 (2013): s.p.

"Las poéticas explícitas de José Ángel Valente y Antonio Colinas. Caracterización de un género". Madrygal 18 (2015): 161-170.

Colinas, Antonio. Sobre la Vida Nueva. Oviedo: Nobel, 1996.

Del pensamiento inspirado, 2 vols. Salamanca: Junta de Castilla y León, Consejería de Educación y Cultura, 2001.

El río de sombra. Treinta y cinco años de poesía, 1967-2002. Madrid: Visor, 2004.

En la luz respirada [contiene los libros Sepulcro en Tarquinia, Noche más allá de la noche y Libro de la mansedumbre]. Madrid: Cátedra, 2004.

El sentido primero de la palabra poética. Madrid: Siruela, 2008.

Un tiempo que no pasa: nuevos ensayos. Valladolid: Universidad de Valladolid, 2009.

Tres tratados de armonía. Barcelona: Tusquets, 2010.

Doncel, Diego. "Sobre Tratado de armonía”. El viaje hacia el centro. La poesía de Antonio Colinas. Antonio Colinas et al. Madrid: Calambur, 1997. 245-251.

Filocalia. Salamanca: Sígueme, 2004.

Guénon, René. Símbolos fundamentales de la ciencia sagrada. Barcelona: Paidós, 1995.

Lucifora, María Clara. "Las autopoéticas como máscaras”, RECIAL 7 (2015): s.p.

Martínez Fernández, José Enrique. "Armonía y ritmo en Antonio Colinas: ajustes métricos en Noche más allá de la noche". Rhythmica 2.2 (2004): 137-158.

Moliner, Luis. "Respirar (En torno a un verso de Antonio Colinas)". Respirar. La palabra poética de Antonio Colinas. Madrid: Devenir, 2007. Contiene los artículos "Respirar (En torno a un verso de Antonio Colinas)", "El Regreso", "Variaciones sobre el centro" y "La palabra abierta ('Invierno tardío')".

Nana Tadoun, Guy Merlin. Antonio Colinas o la escritura como aventura circular: poesía y transtextualidad desde su trilogía final (1992-2002). Salamanca: Vítor, 2008. 
Pallasmaa, Juhani. Los ojos de la piel. La arquitectura y los sentidos. Barcelona: Gustavo Gili, 2014.

Passeron, René. La naissance d'Icare. Éléments de poïétique generale. Marly-le-roi / Valenciennes: ae2cg Éditions / Presses Universitaires de Valenciennes, 1996.

Puerto, José Luis. “Antonio Colinas: La poesía como itinerario de purificación”. El viaje hacia el centro. La poesía de Antonio Colinas. Antonio Colinas et al. Madrid: Calambur, 1997. 41-70. Anteriormente publicado en Cuadernos Hispanoamericanos 556 (1996): 59-84. Relatos de un peregrino ruso. Salamanca: Sígueme, 1992.

Rodríguez, Claudio. Alto jornal. Antología poética. Edición, selección y prólogo Vicente Gallego. Sevilla: Renacimiento, 2005.

Rojas, Gonzalo. Concierto. Antología poética (1935-2003). Selección y prólogo de Nicanor Vélez. Barcelona: Galaxia Gutenberg/Círculo de Lectores, 2004.

Roses Lozano, Joaquín (1990). "Sobre el ingenio y la inspiración en la edad de Góngora". Criticón 49 (1990): 31-49.

Sahagún, Carlos. "Notas sobre la poesía". Poéticas españolas contemporáneas. La generación del 50. Ed. Pedro Provencio. Madrid: Hiperión, 1988. Antes en Francisco Ribes, Poesía última. Madrid: Taurus, 1963. 119-126.

Valente, José Ángel. El fulgor. Antología poética (1953-1996). Barcelona: Galaxia Gutenberg/ Círculo de Lectores, 2000. 